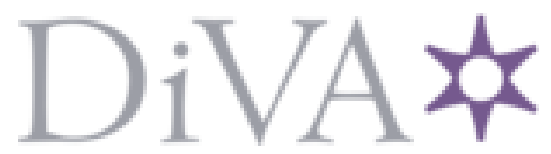

http://www.diva-portal.org

\title{
Postprint
}

This is the accepted version of a paper presented at Probabilistic Methods Applied to Power Systems (PMAPS), 2016 International Conference on, Beijing, 16-20 Oct. 2016.

Citation for the original published paper:

Wallnerström, C J., Bertling Tjernberg, L., Hilber, P., Jürgensen, J H. (2016)

Framework for System Analyses of Smart Grid Solutions with Examples from the Gotland Case.

In: 2016 International Conference on Probabilistic Methods Applied to Power Systems (PMAPS)

https://doi.org/10.1109/PMAPS.2016.7763923

N.B. When citing this work, cite the original published paper.

(c) 2016 IEEE. Personal use of this material is permitted. Permission from IEEE must be obtained for all other users, including reprinting/ republishing this material for advertising or promotional purposes, creating new collective works for resale or redistribution to servers or lists, or reuse of any copyrighted components of this work in other works.

Permanent link to this version:

http://urn.kb.se/resolve?urn=urn:nbn:se:kth:diva-199935 


\section{Framework for System Analyses of Smart Grid Solutions with examples from the Gotland case}

\author{
Carl Johan Wallnerström \\ Lina Bertling Tjernberg \\ School of Electrical Engineering \\ KTH Royal Institute of Technology \\ Stockholm, Sweden
}

\author{
Patrik Hilber \\ Jan Henning Jürgensen \\ School of Electrical Engineering \\ KTH Royal Institute of Technology \\ Stockholm, Sweden
}

\begin{abstract}
This paper presents results from a study on the impact of smart grid solutions, which includes development of a generic framework for power system analyses. The study has been performed as one of several independent studies, part of a national governmental task on smart grid in Sweden. A large amount of weather data, along with electricity consumption and wind power generation data, have been analyzed. Achieved results from these initial analyses can be used as reference material and have also been used within case studies presented.

The proposed framework is flexible and numerous combinations of scenarios are possible to define. Integration of wind and solar power, analyses of transfer limits using static or dynamic rating and energy storage can be considered as well as weather effects. Results show how power systems can handle more electricity consumption and generation. The study shows that Smart Grid solutions are beneficial for resource efficient electricity grids. Moreover, different risk levels with respect to increased load can be included. Case study results show that energy storages most of the time will be unused, but that they can be used to increase the system reliability.
\end{abstract}

Keywords-Dynamic rating, Distributed generation, Energy storage, Smart Grid, Solar power generation, Weather Correlations, Wind power generation, Transfer limits

\section{INTRODUCTION}

$\mathrm{S}^{\mathrm{O}}$ OLUTIONS within the Smart Grid concept are important means for achieving more renewable energy, energy efficiency and less use of fossil fuels [1]. USA, Europe and China invest billions to expand and modernize their grids [2][3][4]. The EU was early by introducing concrete climate goals [5]. In Sweden, the government appointed the Swedish Coordination Council for Smart Grid (henceforth the Council) in 2012. The mission was to coordinate and stimulate cooperation, knowledge transfer and discussions among stakeholders. This resulted in a national action plan for the period 2015-2030 regarding strategic Smart Grid efforts in Sweden. In December 2014, a proposal with an English summary was presented [6]. During the Council's mandate period, it funded a number of different studies [6]. This paper is based on results from one of the aforementioned studies [7].

Solutions within the Smart Grid concept are rapidly evolving and have been analyzed from a huge amount of perspectives [1][3], often from a data communication, monitoring and control perspective such as [8]. In addition, studies of capacity increasing benefits [9] and different solutions to facilitate integration of intermittent distributed generation [10][11][12] have been conducted such as demand response [13][14], energy storage [15] and dynamic rating [16][17] or looking at reliability aspects of this [18]. Studies have been performed on the relationship between weather parameters and power system properties [19].

This paper proposes a framework looking at various solutions from a system perspective largely based on statistical relationships and synergies with weather parameters. This includes dynamic and static rating approaches; integration of wind and solar power, weather dependent electric consumption pattern, energy storage and an option to compare different overloading risk levels. Compared with a paper based on same project presented in 2015 [20], this paper is more comprehensive and focus more on method.

The generic algorithm and assumptions of the framework are presented in Section II. Section III presents input data, information of the area from where data were achieved and initial data analysis results. Section IV proposes details of modules used within the framework - details that can be used generic in some cases but have to be updated with specific data. Analyses and results that demonstrate possible use of the framework are presented in Section V.

\section{PROPOSED FrAMEWORK}

\section{A. Introduction}

Proposed framework is generic and can facilitate studies of power system parts of any size, voltage level and with flexible composition of generation and electricity consumption. The main algorithm of the framework is illustrated as a flow chart in section B. The model contains calculation modules, which are flexible to separately develop and improve, see Section C.

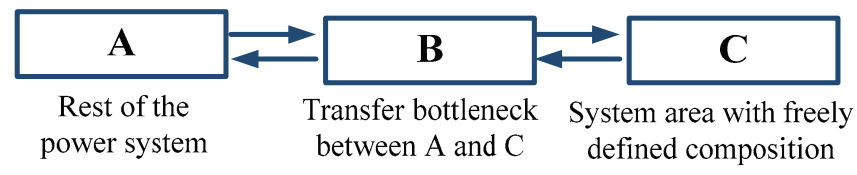

Fig. 1 Illustration of the overall concept

The basic concept is illustrated in Fig. 1: a local system area (C) is connected with the rest of the power system (A) by a set of components with limited transfer capacity (B).

- Block $A$ represents the rest of the power system. From this area it is assumed that desired electrical energy either can be exported to or imported from. 
- Block B symbolizes a link between A and C, where the transfer capacity is limited acting as a bottleneck and may correspond to a set of several components. The transfer capacity can both be modelled as equal or different in both directions. This can in reality correspond to limited transfer by various factors; for example, if generation from solar power gives voltage problems, it might cause different transfer restrictions on imports vs. exports, as opposed to thermal restriction.

- Block $C$ symbolizes a system area. One or several of the following categories are connected: a) electricity consumption, b) wind power, c) solar power and/or d) energy storage. The sizes of these in relation to each other are free to define.

The calculations capture extreme values and are deterministic, apart from the energy storage module; the latter is explained in section D. The approach of the framework is to go through a huge database of hourly weather conditions. This gives a good statistical basis with real measured historical data and decreases the need of using hypothetical assumptions.

\section{B. Overall algorithm}

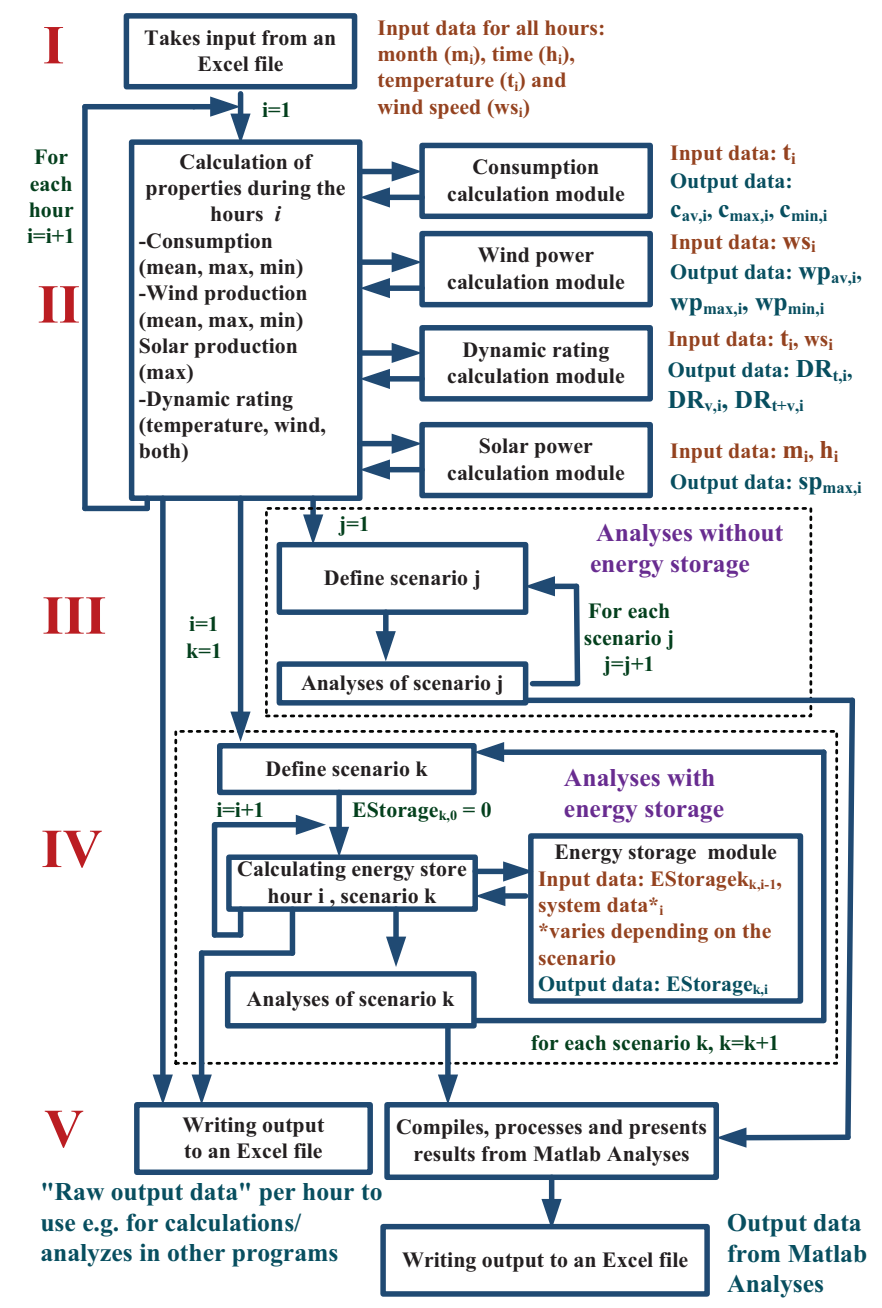

Fig. 2 Flow chart of the overall algorithm
The algorithm of the proposed framework (see Fig. 2):

i. Matlab receives input data from an Excel file. No upper limit for the number of records. For each hour following inputs are given: month (1-12), time (1-24), temperature $\left[{ }^{\circ} \mathrm{C}\right]$ and wind speed $[\mathrm{m} / \mathrm{s}]$.

ii. Hourly calculations: Calculate various properties for each hour by sending inputs to modules and get back results. The modules are described in section $C$.

iii. Analyses are performed by using the large amounts of raw results that were produced during step ii. By defining system characteristics and analysis questions, different analysis results are produced. These are defined before running the entire algorithm.

iv. Energy storage calculations: as in step iii, system properties and analyses questions are defined and results from step $i i$ are used. In addition, a module for energy storage it is used, see section D.

v. Writes results to an Excel document: Examples of possible results are given in Section V.

\section{Included stand-alone modules}

TABLE I summarizes in- and outputs between main algorithm and modules and refers to the section where each is described. All modules can be separately modified independently from the main algorithm. The energy storage algorithm described in section D is system independent. The other modules proposed are described in Section IV. The electricity consumption and generation modules are based on specific data (see Section III). These modules can be used generic, but if the system significantly differs from Swedish properties, these can be modified with other data. The dynamic rating module is component specific and generic for overhead lines, but can be updated if other component(s) constitute bottlenecks.

TABLE I

IN AND OUTPUTS BETWEEN INCLUDED MODULES AND MAIN ALGORITHM

\begin{tabular}{l|l|l|l}
\multicolumn{1}{c|}{ Module } & \multicolumn{1}{|c}{ Input } & \multicolumn{1}{c}{ Output } & Sec. \\
\hline \hline $\begin{array}{l}\text { Energy } \\
\text { storage }\end{array}$ & $\begin{array}{l}\text { EStorage } \mathrm{k}_{\mathrm{i}, \mathrm{i}}, \\
\text { system data }\end{array}$ & $\begin{array}{l}\text { Updated energy storage status } \\
\left(\text { EStorage }_{\mathrm{k}, \mathrm{i}}\right) .\end{array}$ & $\mathrm{D}$ \\
\hline $\begin{array}{l}\text { Electricity } \\
\text { cons. }\end{array}$ & $\begin{array}{l}\text { temperature }\left(t_{i}\right) \\
{\left[{ }^{\circ} \mathrm{C}\right]}\end{array}$ & $\begin{array}{l}\text { Average }\left(c_{a v, i}\right), \max \left(c_{\max , i}\right), \min \\
\left(c_{\min , i}\right) \text { values of e. cons. }[\%] .\end{array}$ & IV.B \\
\hline $\begin{array}{l}\text { Wind } \\
\text { power gen. }\end{array}$ & $\begin{array}{l}\text { wind speed }\left(w s_{i}\right) \\
{[\mathrm{m} / \mathrm{s}]}\end{array}$ & $\begin{array}{l}\text { Average }\left(w p_{a v, i}\right), \max \left(w p_{\max , i}\right) \\
\text { and min }\left(w p_{\min , i}\right) \text { values of wind } \\
\text { power generation }[\%] .\end{array}$ & IV.A \\
\hline $\begin{array}{l}\text { Solar } \\
\text { power gen. }\end{array}$ & $\begin{array}{l}\text { Month }\left(m_{i}\right)(1-12), \\
\text { hour }\left(\mathrm{h}_{i}\right)(1-24)\end{array}$ & $\begin{array}{l}\text { Max value }(\text { only) of solar } \\
\text { power generation }\left(s p_{\max , i}\right)[\%]\end{array}$ & IV.C \\
\hline $\begin{array}{l}\text { Dynamic } \\
\text { rating }\end{array}$ & $\begin{array}{l}\text { temp. }\left(t_{i}\right)\left[{ }^{\circ} \mathrm{C}\right], \\
\text { wind } \mathrm{s} .\left(w s_{i}\right)[\mathrm{m} / \mathrm{s}]\end{array}$ & $\begin{array}{l}\text { Dynamic ratings from } 3 \text { models } \\
\left(D R_{t, i}, D R_{v, i}, D R_{t+v, i}\right)[\%]\end{array}$ & IV.D \\
\hline
\end{tabular}

\section{Energy storage algorithm}

The analyses produce specifications of requirements for energy storage and did not depend on energy storage technique used (i.e. not need to be a battery). EStorage ${ }_{i}$ is the energy storage status regarding hour $i$. EStorage ES $_{i}=0$ does not necessarily mean empty energy storage, but its "normal level". Required size and the normal level are determined after EStorage $_{i}$ have been calculated for all hours., see (8).

Unlike the other models proposed, this calculation model use both deterministic and stochastic parts. Current status of the energy storage is based on current hour and earlier hours. The probability of a worst case situation during a specific hour is 
not negligible, but having that situation constantly during many hours or even several days is unlikely. Such assumption would give unrealistic demands on the energy storage. However, it is important with conservative calculations. A compromise is that a value between the mean and the worst case extreme value is randomized, uniform distribution " $u(a, b)$ ". Since it can be used to both handle import and export restrictions, two different pessimistic values are calculated, see (1)-(6); $[s p],[w p]$ and $[c]$ are the peak value of each category in relation to the import capacity, e.g. $[c]>1,[s p]=[w p]=0$ means an import overload risk and no electricity generation.

$$
\begin{aligned}
& E G_{1}=[s p] * \mathrm{sp}_{\max , i}+[w p] * u\left(\mathrm{wp}_{a v, i}, \mathrm{wp}_{\max , i}\right) \\
& E G_{2}=[w p] * u\left(\mathrm{wp}_{\min , i}, \mathrm{wp}_{a v, i}\right) \\
& E C_{1}=[c] * u\left(\mathrm{c}_{a v, i}, \mathrm{c}_{\max , i}\right) \\
& E C_{2}=[c] * u\left(\mathrm{c}_{\min , i}, \mathrm{c}_{a v, i}\right)
\end{aligned}
$$

High import level stochastic estimation $=E C_{1}-E G_{2}(5)$ High export level stochastic estimation $=E G_{1}-E C_{2}$ (6)

$\mathrm{EG}_{1}$ and $\mathrm{EG}_{2}$ are upper and lower estimates of electricity generation respectively and $\mathrm{EC}_{1}$ and $\mathrm{EC}_{2}$ are upper and lower estimates of electricity consumption. If the electricity import is higher than the transfer capacity, the energy storage needs to deliver electrical energy to decrease the import needs (the opposite in case of export problems). Hence, it should be charged as preparedness when possible. If no transfer limits are reached, the energy storage return to its normal level as fast as possible with considered transfer constraints.

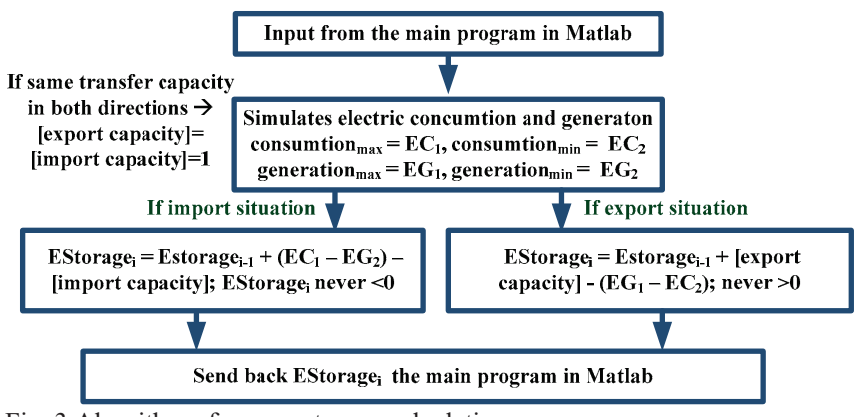

Fig. 3 Algorithm of energy storage calculations

The algorithm is illustrated in Fig. 3. EStorage $_{i}$ has the unit "hour". When EStorage $i$ is multiplied afterwards by a transfer limit with the unit power (e.g. MW), it gives the unit of energy (e.g. MWh), see (7). Power requirements are calculated by taking the highest absolute value of the difference between EStorage $_{i}$ and EStorage $_{i-1}$ in both directions.

$$
\begin{aligned}
& {[\text { Energy storage size needed }]=[\text { transfer limit }] * \text {. }} \\
& \left.\left(\text { Max }_{\text {EStorage }}\right)-\text { Min }\left(\text { EStorage }_{i}\right)\right) \\
& {[\text { Normal level }]=\frac{- \text { Min }\left(\text { EStorage }_{i}\right)}{[\text { Energy storage size needed }]}}
\end{aligned}
$$

Assume that EStorage $_{i}$ vary between -2.5 and +10 during all hours analyzed and a transfer limitation of $1 \mathrm{MW}$. Then an energy storage of $12.5 \mathrm{MWh}$ is needed $(=10-(-2.5))$ and the normal level is $20 \%$ charged $\left(\frac{-(-2.5)}{10-(-2.5))}\right)$, i.e. $2.5 \mathrm{MWh}$.

\section{INPUT DATA AND INITIAL ANALYSES}

The methods proposed are demonstrated by using input data from Gotland, the largest island in the Baltic Sea that is hosting a national Smart Grid demonstration project, see section C.

\section{A. Data sources used}

Hourly data of electric consumption and wind power generation were obtained for the period October 2011 to September 2012 from the distribution system operator of Gotland, GEAB [14].

Stakeholders within the power and energy sector have a potential to utilize free data [21], e.g. weather data. The benefits of good weather data will increase further due to more renewable energy and smart grid concepts [17]. There is a tendency towards free and open public data. Within the EU, the Directive 2003/98/EC encourages that public information should be free for re-use as much as possible.

The Swedish Meteorological and Hydrological Institute (SMHI) is a governmental body that recently has made both historical and real-time data freely available [22]. Hourly weather data between 1970 and 2003 at Visby Airport has been retrieved from SMHI. In addition, weather data have been gathered for a shorter rime period from Huborg, another weather station at Gotland. Long data series are important to capture improbable risks and to achieve high statistical validation when different scenarios are studied. Visby Airport was chosen because it has a long data series, has a high costumer density and is close to the mainland link. However, Huborg is located on the southern tip close to a considerable part of Gotland's wind power capacity.

\section{B. Power system of Gotland}

An advantage of using Gotland as a case study is that it is an isolated power system with a suitable size [23]. There are already major challenges for renewable distributed generation. The amount of wind power has reached the upper ceiling that can be handled with existing technology and infrastructure.

Gotland is connected to the mainland via an HVDC link. And a VSC link (HVDC Light) has also been built to transfer the large amounts of wind power from Huborg to the area around Visby. In 2011, the total installed wind power capacity was $170 \mathrm{MW}$ and with current technology and infrastructure the power system is expected to handle $195 \mathrm{MW}$. The electricity production was $340 \mathrm{GWh}$ in 2011, representing $38 \%$ of Gotland's electricity consumption. However, wind power generation and electricity consumption are unevenly spread over the year, which result in import and export peaks.

\section{Large scale demonstration projects}

As new technologies and solutions involve unknown risks and opportunities, it is valuable to complement theoretical research and commercial developments with large-scale Smart Grid demonstration sites. Reference [24] exemplifies such European projects. Three projects are ongoing in Sweden: the Royal Seaport, Hyllie, and Smart Grid Gotland. All projects are focused on different Smart Grid aspects.

Smart Grid Gotland is a development and demonstration projects to illustrate and investigate possibilities to modernize an existing power system to handle more renewable energy, while maintaining or improving power quality [25]. 


\section{Initial data analyses \\ 1) Correlations}

Some Smart Grid solutions are directly affected by weather parameters [7]. At the same time, the capacity requirements of components often indirectly depend on the weather in different ways. Hence it is valuable to investigate the weather dependency of power system utilization. Heating and air condition are examples of human behavior that depend on outdoor temperature and that affect the electricity consumption; in Sweden it gives a negative correlation between temperature and consumption [26].

The tendency of increased amount of intermittent distributed generation gives situations where the power line congestion depends on the weather [7]. An example is the dependency between wind power production and wind speed; a weather parameter that also affect the dynamic capacity of overhead lines [27] (see section IV.D).

TABLE II provides correlations between wind power generation, electricity consumption, wind speed and outdoor temperature. Note, electric generation and consumption refer to entire Gotland, while the weather parameters are only from the Visby Airport. Correlation between electricity generation and consumption is interesting to study if it is a bottleneck to an area with both of these. Generation and consumption can in these cases cancel each other [7]; how much depends e.g. indirectly on weather parameters, see Section V.A.

TABLE II

CORRELATION BETWEEN INPUT DATA IN THIS STUDY

\begin{tabular}{r||r|r|r} 
& Generation & Consumption & Temperature \\
\hline \hline Consumption & 0.22 & & \\
\hline Temperature & -0.05 & -0.71 & -0.04 \\
\hline Wind speed & 0.84 & 0.22 & \\
\hline
\end{tabular}

2) Temperature dependency

Fig. 4 shows the average value of electricity consumption, wind power generation, and net imports as a function of temperature. The wind power generation dependency can be explained by high pressure with low wind speed which is common when it is hot or cold. Higher wind speeds in average occur during spring and fall.

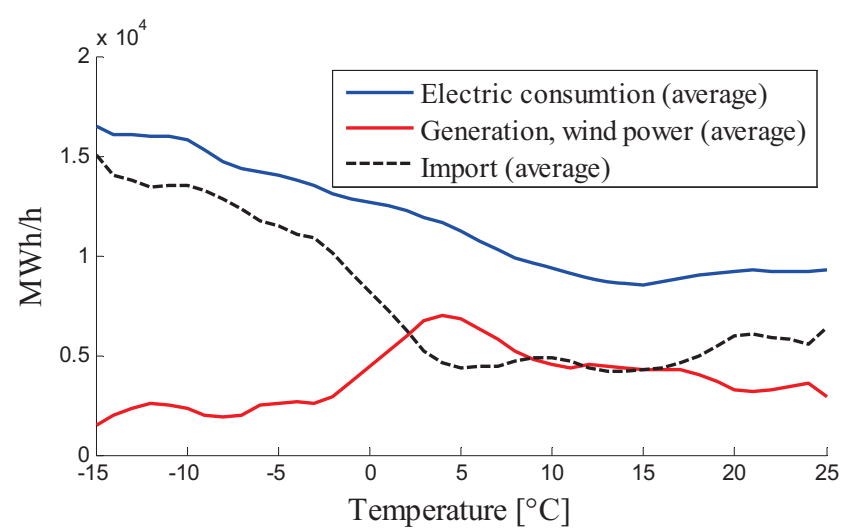

Fig. 4 Average electricity consumption, wind power generation and import as a function of as a function of outdoor temperature

The electricity consumption's temperature dependency is low when the temperature is low or high, but in midrange it is almost linear. That could be explained by maximal heating at about $-10^{\circ} \mathrm{C}$ and that most households do not heat above $15^{\circ} \mathrm{C}$. These tendencies have also been observed in other studies [28]. A model for calculating the average, max and min values of electricity consumption as a function of temperature has been developed motivated by this strong correlation. This model is presented in section IV.B. When it comes to electricity consumption, it is unlikely that it will reach over $80 \%$ of the peak value if the temperature is $>0^{\circ} \mathrm{C}$ and in the summer it rarely reach $>60 \%$. That is positive within many dynamic rating approaches (see Section IV.D) and together with other models developed in proposed framework several other synergies can be captured.

\section{3) Validation, comparison with another study}

Because Gotland has a high share of industry customers, a hypothesis is that the correlation between temperature and electricity consumption is lower compared with an average Swedish power distribution system. The correlation of another Swedish power system (Ekerö, a semi-rural area close to Stockholm) [28] was "-0.90" compared to "-0.71" for Gotland. Results from this previously conducted study were presented in 2010 with the aim to study the dependency between the weather and electricity consumption [28]. Fig. 5 shows all hourly measurements of temperature vs. electricity consumption of Ekerö including the average trend. Compared to Gotland, there are many similarities. The conclusion is that the module presented in section IV.B, which are based on Gotland data, provides a statistical relationship whose shape is similar to other Swedish power systems.

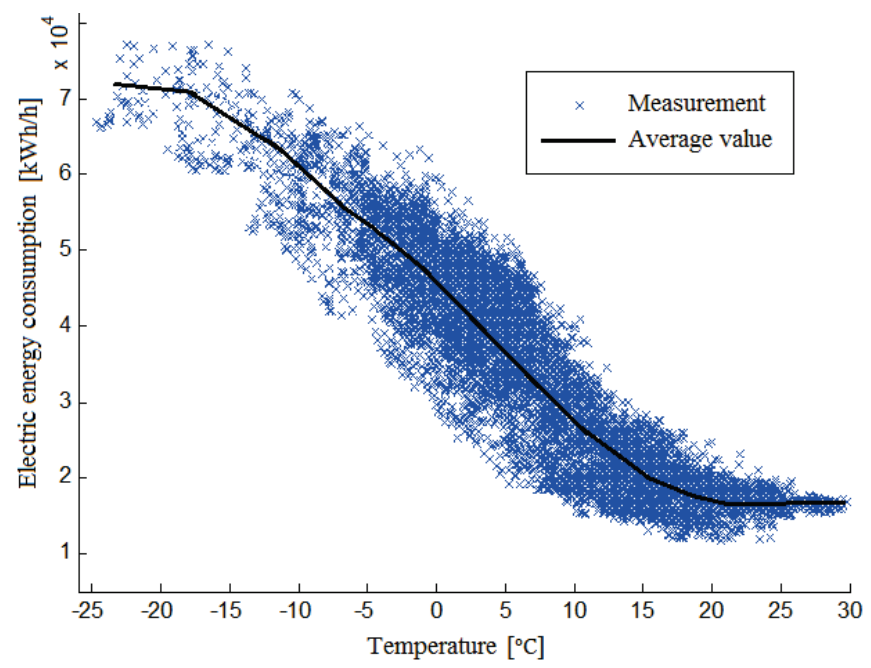

Fig. 5 Ekerö power system: Electricity consumption as the function of temp. 
4) Wind speed dependency

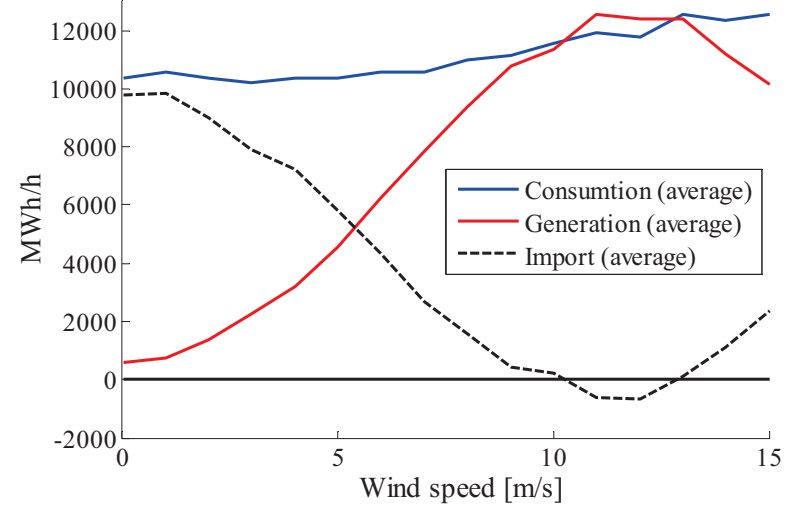

Fig. 6 Average electricity consumption, wind power generation and import as a function of as a function of wind speed

A model for calculating the average, max and min values of wind power generation as a function of wind speed has been developed, see section IV.A. The difference between possible extreme values of wind power generation is high over all wind speed intervals. This makes wind power generation less predictable than e.g. electricity consumption. This is essential to consider in order capturing worst case scenarios.

\section{5) Seasonal variations}

TABLE III

MAXIMUM AND MINIMUM VALUES BASED ON SEASONS

\begin{tabular}{l|r|r|r|r|r}
\hline \hline \multirow{2}{*}{ Seasons $^{3}$} & Electric energy consumtion & & \multicolumn{2}{c}{ Wind power gener. } \\
\cline { 2 - 6 } & Average & \multicolumn{1}{c}{ Max } & \multicolumn{1}{c}{ Min } & Average & \multicolumn{1}{c}{ Max } \\
\hline \hline Spring & $53 \%$ & $81 \%$ & $7 \%$ & $31 \%$ & $100 \%$ \\
\hline Summer & $44 \%$ & $59 \%$ & $19 \%$ & $23 \%$ & $97 \%$ \\
\hline Fall & $51 \%$ & $72 \%$ & $7 \%$ & $35 \%$ & $98 \%$ \\
\hline Winter & $68 \%$ & $100 \%$ & $45 \%$ & $43 \%$ & $98 \%$ \\
\hline 1 The annual high $=100 \%$, in this example equivalent to $195900 \mathrm{kWh} / \mathrm{h}$. \\
2 The annual high $=100 \%$, in this example equivalent to $151500 \mathrm{kWh} / \mathrm{h}$. \\
3 Spring = Mar-May; Sum. = Jun-Aug; fall = Sep-Nov; Winter = Dec-Feb. \\
\hline
\end{tabular}

TABLE III exemplifies the average, max and min electricity consumption and wind power generation if the year is divided into four seasons. The min wind power generation is $0 \%$ despite season and is omitted in the table.

\section{ADDITIONAL MODULES PROPOSED}

See introduction in section II.C, where in- and outputs from/to the main generic algorithm are also defined.

\section{A. Wind power generation}

TABLE IV

ELECTRIC ENERGY WIND POWER PRODUCTION MODEL

\begin{tabular}{|c|c|c|c|c|}
\hline \multirow{2}{*}{$\begin{array}{c}\text { Wind s. } \\
{[\mathrm{m} / \mathrm{s}]^{*}}\end{array}$} & \multirow{2}{*}{$\begin{array}{c}\text { Share } \\
{[\%]}\end{array}$} & \multicolumn{3}{|c|}{ Electric energy gen. [\% of peak value] } \\
\hline & & $w p_{\min , i} * *$ & $w p_{a v, i} * *$ & $w p_{\max , i}{ }^{* *}$ \\
\hline$<1.5$ & 7.9 & 0 & 5 & 20 \\
\hline $1.5-2.5$ & 12.2 & 0 & 9 & 29 \\
\hline $2.5-3.5$ & 12.5 & 0 & 15 & 43 \\
\hline $3.5-4.5$ & 16.2 & 0 & 21 & 54 \\
\hline $4.5-5.5$ & 11.5 & 0 & 30 & 68 \\
\hline $5.5-6.5$ & 12.1 & 0 & 41 & 84 \\
\hline $6.5-7.5$ & 9.5 & 0 & 52 & 96 \\
\hline $7.5-8.5$ & 5.9 & 20 & 62 & 100 \\
\hline $8.5-9.5$ & 5.6 & 32 & 71 & 100 \\
\hline $9.5-15.5$ & 6.8 & 44 & 79 & 100 \\
\hline$>15.5$ & 0.1 & $0^{* * * *}$ & 42 & 100 \\
\hline
\end{tabular}

*Wind speed measured at a single local weather station

$* *$ Regarding a wider area, same region as the weather station

*** Extreme weather can lead to $0 \%$ generation in an area.

The model is based on analyses presented in section III.D and is presented in Table IV. Note, low wind speeds can give generation which is explained in section III.D.4).

\section{B. Electricity consumption}

TABLE V

ELECTRIC ENERGY CONSUMPTION MODEL

\begin{tabular}{|c|c|c|c|c|}
\hline \multirow{2}{*}{$\begin{array}{c}\text { Temp. } \\
{\left[{ }^{\circ} \mathrm{C}\right]} \\
\end{array}$} & \multirow{2}{*}{$\begin{array}{c}\text { Share } \\
{[\%]} \\
\end{array}$} & \multicolumn{3}{|c|}{ Electric energy cons. [\% of peak value] } \\
\hline & & $c_{\min , i}$ & $c_{a v, i}$ & $c_{\max , i}$ \\
\hline$<-10$ & 1.46 & 67 & 83 & 100 \\
\hline-10 to -5 & 2.15 & 54 & 74 & 94 \\
\hline-5 to 0 & 10.14 & 49 & 67 & 85 \\
\hline 0 to 5 & 26.05 & 43 & 61 & 78 \\
\hline 5 to 10 & 24.06 & 34 & 51 & 69 \\
\hline$>10$ & 36.15 & 32 & 45 & 58 \\
\hline
\end{tabular}

Estimated averages for different temperature ranges are based on the initial analysis in section III.D. The unit is percentage of its peak value, while max and min values are 2 standard deviations from the mean (normal distribution is assumed) and validated against real input data. The model is presented in Table V. Extreme values are important to capture worst case.

\section{Solar Power generation}

The model calculates the peak production at perfect conditions based on how high the sun is over the horizon in Visby [29]. The peak value is equal to $100 \%$ in Table VI that only gives max values, $s p_{\max , i}$, as function of time and month. This is justified because the model focuses on the worst case and that the min value is assumed to always be zero. 
TABLE VI

ELECTRIC ENERGY PRODUCTION MODEL FROM SOLAR POWER

Month [1-12]

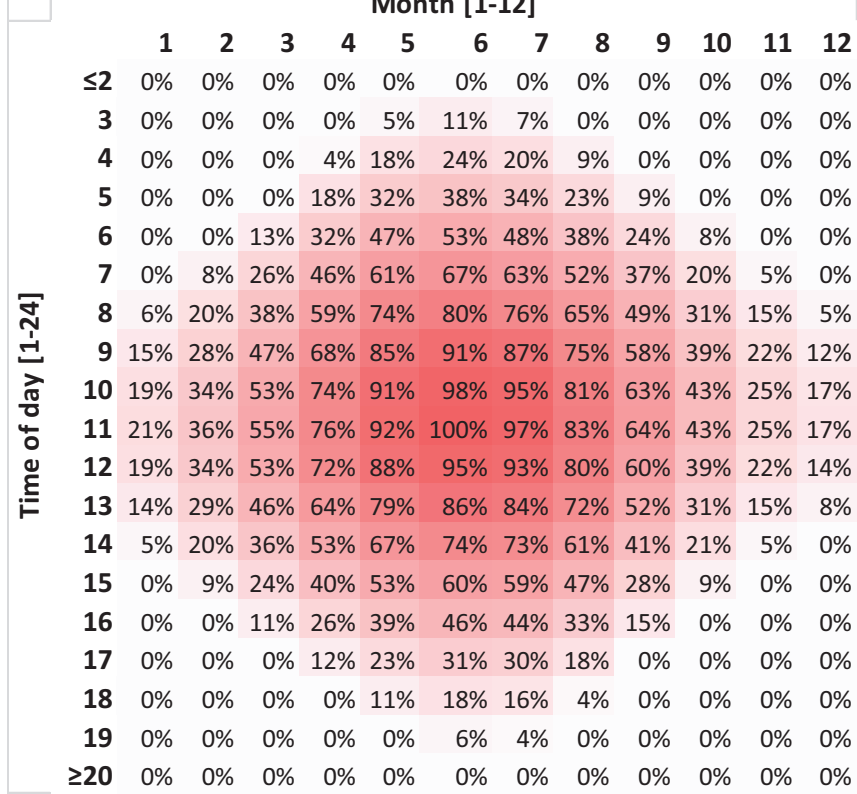

D. Dynamic rating introduction, assumptions and model used

$\mathrm{OH}$ line dynamic rating is used because several case studies have been conducted in Sweden [30]. It is possible to replace this module with other dynamic rating models or to expand it with more power component models. For example, R\&D has been conducted regarding power transformers than can be included in future versions.

\section{1) Introduction}

Wind power generation has a correlation with the weather in a positive way [18], i.e. high generation correlates with high dynamic transfer capacity. Furthermore, in Sweden there are positive correlation between low temperature and high energy consumption [7]. A challenge is that the measured wind speed often is optimistic to use since the wind speed is neither the same through the entire line nor perpendicular. To handle this, a scale parameter can be introduced, that scale down the available wind speed input data to have a margin [17].

IEEE standard 738 [27] provides a formula for calculating max current allowed of bare $\mathrm{OH}$ conductors. Based on this, a dynamic rating calculation model has been developed, see [17]. The method is simplified to be implemented in the daily operation. Evaluations performed conclude that its results only differ minimal from more complex models [17]. The proposed model gives the dynamic line capacity $\left(D L R_{x}\right)$ as a function of static line capacity, wind speed and/or ambient temperature. $D L R_{x}$ is the capacity factor compared to traditional static rating. If e.g. the static rating is $3 \mathrm{MW}$ and $D L R_{x}$ is 2 , the new dynamic rating is equal to $6 \mathrm{MW}$.

2) Outdoor temperature part

$D L R_{t} \approx \frac{\sqrt{\left(\mathrm{t}_{\max }-t_{i}\right)}}{\sqrt{\left(\mathrm{t}_{\max }-\mathrm{t}_{S L R}\right)}}=c 1 *\left(\mathrm{t}_{\max }-t_{i}\right)^{0.5}$

In (9), $t_{\max }$ is the maximal line temperature allowed, $\mathrm{t}_{S L R}$ is the worst case outdoor temperature that static rating is based on, $t_{i}$ is the outdoor temperature that is input to the calculation and $c 1$ is a constant defined in [17].
3) Wind speed part

$D L R_{v} \approx \max \left\{\begin{array}{c}1 \\ c 2 * v_{i}^{0,26} \\ c 3 * v_{i}^{0,30}\end{array}\right.$

In $(10), v_{i}$ is the wind speed. For information of how to calculate $c 2$ and $c 3$, see [17].

4) Using both temperature and wind speed as input

The contribution of wind speed and outdoor temperature can be approximately assumed to be independent of each other [17] and thus can be calculated by multiplying the respective contribution from (9) and (10) to each other, see (11): $D L R_{t+v} \approx D L R_{v} * D L R_{t}$

\section{EXAMPLES OF ANALYSES With RESUltS}

A. Correlations and synergies to handle transfer limits TABLE VII

TRANSFER CAPACITY OF DYNAMIC RATING COMPARED WITH STATIC

\begin{tabular}{l||r|r|r}
\multicolumn{1}{c||}{} & \multicolumn{3}{c}{$\begin{array}{c}\text { Static rating }=\mathbf{1 0 0} \% \text {, max of: } \\
\text { Cons. }\end{array}$} \\
DR that consider: & Wind power & Solar power \\
\hline \hline Temperature & $134.4 \%$ & $101.9 \%$ & $103.2 \%$ \\
\hline Wind speed & $100.0 \%$ & $219.2 \%$ & $100.0 \%$ \\
\hline Both & $134.4 \%$ & $224.1 \%$ & $112.3 \%$ \\
\hline
\end{tabular}

Table VII exemplifies results from dynamic rating analyses, where the potential of taking advantages of identified weather correlations had been investigated. $100 \%$ corresponds to the transfer limit with classic static rating, i.e. having a constant rating all the time based on worst case circumstances.

Potential benefits of using synergies between electricity consumption and generation have been analyzed, i.e. how these factors cancel each other in a mixed system part. Increased average electricity consumption provides the ability to handle more generation. Even with pessimistic assumptions, each MW of peak electricity consumption, make additional $0.32 \mathrm{MW}$ more electric generation possible. To increase electric consumption if intermittent generation increases is however not possible since the electricity generation can be 0 . With a variety of smart solutions, where electricity consumption and/or generation can be controlled, the benefits of utilizing such synergies can probably increase more.

TABLE VIII shows results analyzing transfer limitation to mixed system parts. These analyses capture synergies of both dynamic rating and taking advantage of cancelation at the same time. These two effects sometimes becomes stronger compared with just adding one of these two solutions.

Overload with manageable consequences can sometimes be acceptable. It may be useful to take this risk to manage peaks which seldom occurs. It is also possible with alternative solutions not included in this study e.g. smart agreement of electricity generation or demand response. 
TABLE VIII

ANALYSES OF NODES WITH BOTH ELECTRIC PRODUCTION AND CONSUMPTION

\begin{tabular}{|c|c|c|c|c|c|}
\hline \multirow{2}{*}{$\begin{array}{l}\text { Allowed } \\
\text { amount } \\
\text { of }^{1} \text { : }\end{array}$} & \multirow{2}{*}{$\begin{array}{l}\text { Combined } \\
\text { with }^{2} \text { : }\end{array}$} & \multicolumn{4}{|c|}{ [\%] with different rating approaches } \\
\hline & & SLR $^{3}$ & DLR $_{t}$ & $\operatorname{DLR}_{\mathrm{v}}$ & DLR $_{t+v}$ \\
\hline $\begin{array}{l}\text { Wind } \\
\text { power }\end{array}$ & E. cons. & 132.0 & 133.9 & 251.6 & 257.4 \\
\hline $\begin{array}{l}\text { Solar } \\
\text { power }\end{array}$ & E. cons. & 132.0 & 135.5 & 132.0 & 144.3 \\
\hline E. cons. & $\begin{array}{l}\text { Wind } \\
\text { power }\end{array}$ & unchanged & 134.4 & unchanged & 134.4 \\
\hline E. cons. & Solar power & unchanged & 147.1 & unchanged & 147.1 \\
\hline
\end{tabular}

1: Compared with either only electric production or consumption combined with static rating. That base case is set to $100 \%$.

2: It is assumed that annual max electric consumption and production in the node is equal in the base case and only one of them is increased.

3: $\mathrm{SLR}=$ static line rating

If accepting a low probability of overload $1 \%$ of the time, the electricity consumption can increase with $6.4 \%$ and $10 \%$ of the time gives $17.6 \%$ increment possible. This does not mean that there is an overload $1 \%$ or $10 \%$, just a low probability during that time. Regarding solar power generation, these figures are $105.3 \%$ and $147.1 \%$ respectively. For wind power generation even the higher risk level exemplified does not lead to more allowed installation.

\section{B. Energy storage}

1) Energy storage to handle transfer limits TABLE IX

LIST OF ENERGY STORAGE REOUIREMENTS

\begin{tabular}{|c|c|c|c|c|c|c|c|c|c|}
\hline \multirow{2}{*}{$\begin{array}{l}\operatorname{Max}^{1} \\
{[\%]} \\
\end{array}$} & \multicolumn{3}{|c|}{103} & \multicolumn{3}{|c|}{107.5} & \multicolumn{3}{|c|}{112} \\
\hline & $\mathrm{C}$ & $\mathbf{W}$ & $\mathbf{S}$ & $\mathrm{C}$ & $\mathbf{W}$ & $\mathbf{S}$ & $\mathrm{C}$ & $\mathbf{W}$ & $\mathbf{S}$ \\
\hline Size $^{2}$ & $\begin{array}{r}8 . \\
0\end{array}$ & $\begin{array}{r}9 . \\
2\end{array}$ & $\begin{array}{r}3 . \\
9\end{array}$ & $\begin{array}{r}34.4 \\
1\end{array}$ & $\begin{array}{r}37 . \\
7\end{array}$ & $\begin{array}{r}17 . \\
1\end{array}$ & $\begin{array}{r}179 . \\
3\end{array}$ & $\begin{array}{r}128 . \\
1\end{array}$ & $\begin{array}{r}36 . \\
5\end{array}$ \\
\hline $\begin{array}{l}\text { Usage } \\
3\end{array}$ & $\begin{array}{c}0 . \\
1 \\
\end{array}$ & $\begin{array}{r}2 . \\
0\end{array}$ & $\begin{array}{r}1 . \\
0\end{array}$ & 0.39 & 6.3 & 2.4 & 1.2 & 12.4 & 4.5 \\
\hline $\begin{array}{l}\text { Power } \\
4\end{array}$ & $\begin{array}{l}3 . \\
0\end{array}$ & $\begin{array}{r}3 . \\
0\end{array}$ & $\begin{array}{r}3 . \\
0\end{array}$ & 7.5 & 7.5 & 7.5 & 12.0 & 12.0 & $\begin{array}{r}12 . \\
0\end{array}$ \\
\hline
\end{tabular}

1: Maximum electric consumption or production where $100 \%$ is without energy storage. $\mathrm{C}=$ consumption, $\mathrm{W}=$ wind power, $\mathrm{S}=$ solar power.

2: Energy storage size needed in relation to system size. If for example $100 \%=200 \mathrm{MW}$, then size $=$ " 10 " means $20 \mathrm{MWh}$ and " 15 " means 30 MWh.

3: Share [\%] of time the energy storage is in use.

4: How fast it must be capable of charging/delivering electric energy

Energy storage specifications as a function of a variable parameter to handle transfer limitations regarding different scenarios are presented in TABLE IX.

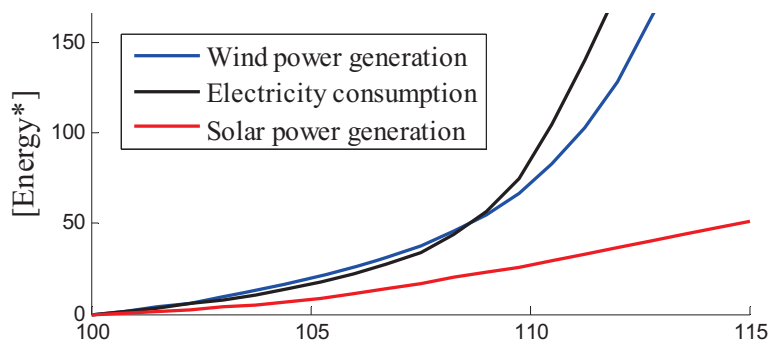

[\% of how much that can be installed without energy storage] Fig. 7 Comparing energy storage size needed

Fig. 7 illustrates a general comparison of how large energy storage is required to the three categories analyzed. Solar power generation is more advantageous compared with electricity consumption and wind power generation. The significant difference can be explained by that the peak generation from solar power only last few hours during summer during days, making time to restore the energy storage to its normal level before the next peak. For the other two, there are longer periods with peak values with no time to restore. However, it would probably result in a more favorable outcome for using energy storage if the model considered electricity patterns between different times of the day.

Analysis results of energy storage to manage a mixed system part which has periods of both import and export transfer limitations are provided in TABLE X. Electricity consumption with solar power generation is exemplified. Note that energy storage size to handle electricity consumption is low compared to results presented in TABLE IX. That indicates that positive synergies of using both energy storage and taking advantage of cancelation effects.

TABLE $\mathrm{X}$

ENERGY STORAGE REQUIREMENTS IN A MIXED SYSTEM PART

\begin{tabular}{l|r|r|r|r|r|r|r|r} 
Cons. ${ }^{1}$ : & \multicolumn{3}{|c|}{$\mathbf{1 0 5}$} & \multicolumn{1}{|c}{$\mathbf{1 0 0}$} & $\mathbf{1 0 2 . 5}$ & $\mathbf{1 0 5 . 5}$ & $\mathbf{1 0 8 . 5}$ \\
\hline $\begin{array}{l}\text { Solar } \\
\text { p. }{ }^{1} \text { : }\end{array}$ & $\mathbf{1 3 2}$ & $\mathbf{1 3 7}$ & $\mathbf{1 4 3}$ & $\mathbf{1 4 9}$ & \multicolumn{5}{|c}{$\mathbf{1 5 0}$} \\
\hline \hline Size $^{2}$ & 16.4 & 20.3 & 33.0 & 50.7 & 43.8 & 46.2 & 56.0 & 85.7 \\
\hline Normal $^{3}$ & 100 & 81 & 50 & 32 & 0 & 12 & 34 & 60 \\
\hline Usage $^{4}$ & 0.2 & 0.3 & 1.0 & 2.3 & 2.9 & 2.8 & 2.6 & 2.7 \\
\hline Power $^{5}$ & 0.0 & 3.4 & 9.4 & 15.4 & 18.0 & 17.2 & 16.2 & 15.3 \\
\hline Power2 $^{5}$ & 5.0 & 5.0 & 5.0 & 5.0 & 0.0 & 2.5 & 5.5 & 8.5
\end{tabular}

1: Maximum electric consumption or production where $100 \%$ is without energy storage and without consider positive synergy effects.

2: Energy storage size needed in relation to system size. If for example $100 \%=200 \mathrm{MW}$, then size $=$ " 10 " means $20 \mathrm{MWh}$ and " 15 " means 30 MWh.

3: How many percentage charged in standby when not in use

4: Share [\%] of time the energy storage is in use.

5: How fast it must be capable of charging/delivering electric energy

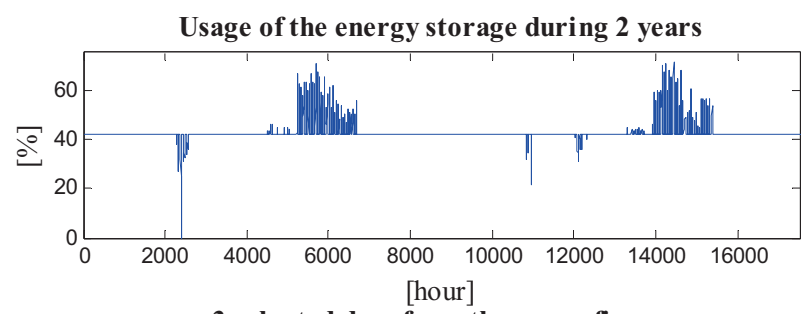

3 selected days from the upper figure

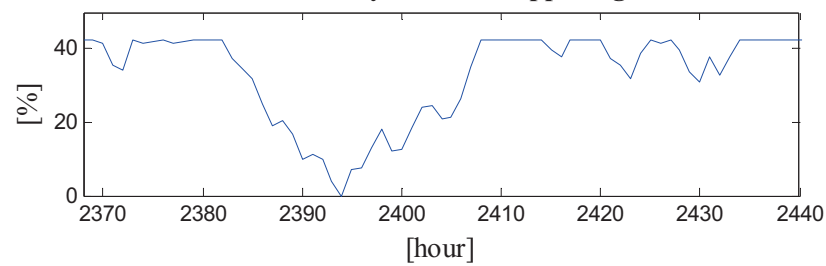

Fig. 8 Example of how an energy storage that handle both high electric generation and consumption is used

Fig. 8 exemplifies how the energy storage level may vary over time regarding a node with $106.5 \%$ electricity consumption and $150 \%$ solar power generation, where the energy storage is charged to about $42 \%$ in standby. The analysis extends over 40 years, 2 of these years are illustrated in the upper part of the figure. The energy storage during these two exemplified years never reaches its highest level. Clear seasonal variations can be discerned. Three days are showed in 
the lower part to get a detailed picture of how the energy storage may vary during a short period. These days are selected at the time when the energy storage was lowest.

\section{2) Additional Energy storage analyses}

Another aspect is that energy storage is unused during most hours of the year. The possibilities of using energy storage to other applications, such as improving reliability, have been investigated. This is more straightforward to do regarding scenarios where energy storage is used to manage electricity consumption as energy storage is fully charged during normal operation (compared with generation when it is normally empty). Furthermore, this scenario has the lowest utilization.

TABLE XI shows the percentage of time the energy storage is unused, size and how long outages it theoretically can be handled at low and high load. Energy storages to handle peak generation need to be empty during normal operation. Thus, these are not available when there is a transfer limitation risk, but can be used during low risk periods. This risk can be predicted by weather forecasts, season and time of day. Solar power generation can reach to over $90 \%$ of its max generation only $\sim 3 \%$ of the time and over $80 \%$ during $\sim 6 \%$. Another positive aspect is that the summer months have few outages compared to the rest of the year in Sweden [26].

TABLE XI

THE POSSIBILITY OF AN ENERGY STORAGE PRIMARY USED TO HANDLE OVERLOADING TO ALSO HANDLE OUTAGES WHEN AVAILABLE

\begin{tabular}{r|r|r|r|r}
\hline \hline \multirow{2}{*}{$\begin{array}{l}\text { Max electric cons. } \\
\text { allowed [\%] }\end{array}$} & \multicolumn{1}{c|}{$\begin{array}{c}\text { Not in } \\
\text { use [\%] }\end{array}$} & Size $^{\mathbf{2}}$ & \multicolumn{2}{|c|}{ Length possible to mitigate } \\
\cline { 4 - 5 } & & & \multicolumn{1}{|c|}{ high load } & \multicolumn{1}{c|}{ low load } \\
\hline \hline 101 & 99.97 & 2 & 1.2 & 3.6 \\
\hline 105 & 99.80 & 15 & 9 & 27 \\
\hline 110 & 99.10 & 85 & 51 & 153 \\
\hline 115 & 98.13 & 378 & 227 & 680 \\
\hline
\end{tabular}

1: Maximum electric consumption where $100 \%$ is without energy storage.

2: Energy storage size needed in relation to system size. If for example $100 \%=200 \mathrm{MW}$, then size $=$ " 10 " means $20 \mathrm{MWh}$ and " 15 " means 30 $\mathrm{MWh}$

3: Minutes a full energy storage can compensate an outage

\section{CONCLUSIONS}

This paper proposes a framework to analyze different smart grid solutions from a system perspective. Developed methods include wind and solar power, electricity consumption, dynamic rating and energy storage. An essential part is to consider effects of weather parameters to find synergies. Initial data analyses results can beside input to other part of the paper be useful as reference material in other studies.

In summary, the study shows that Smart Grid solutions that consider weather synergies are beneficial for resource efficient electricity grids. Energy storage is analyzed from a technique neutral perspective and results are presented as requirement lists. Size requirement to manage electric consumption and wind power generation is increasing exponentially as a function of overload needed to be handled. When more than one solution is implemented at the same time, the positive effect often is higher compared with adding results regarding single solutions, which show that useful synergies can be captured. Using energy storage to increase the reliability during time being unused has also been investigated.

\section{REFERENCES}

[1] P. van den Oosterkamp, P. Koutstaal, A. van der Welle, J. de Joode, J. Lenstra, K. van Hussen and R. Haffner, "The role of DSOs in a Smart Grid environment," European Commission, DG ENER, Amsterdam/Rotterdam, 2014.

[2] Office of Electricity Delivery \& Energy Reliability, "Recovery Act: Smart Grid Investment Grants," (DOE), U.S. Department of Energy, [Online]. Available: http://energy.gov/oe/technology-development/smartgrid/recovery-act-smart-grid-investment-grants [Accessed Dec. 16 2014].

[3] European Commission Joint Research Centre (JRC), "Smart Grid Projects Outlook 2014," [Online]. Available: http://ses.jrc.ec.europa.eu/sites/ses.jrc.ec.europa.eu/files/u24/2014/report /ld-na-26609-en-n_smart_grid_projects_outlook_2014_-_online.pdf [Accessed 1212 2014].

[4] Special Report by Zpryme's Smart Grid, "China: Rise of the Smart Grid," 12011 [Online]. Available: https://www.smartgrid.gov/sites/default/files/doc/files/China_Rise_Smar t Grid 201103.pdf

[5] L. Bertling Tjernberg, "The Smart Grid Experience in Europe," IEEE Smart Grid NewsLetter, Aug 2014:: http://smartgrid.ieee.org/august2014/1132-the-smart-grid-experience-in-europ\%C3\%A9

[6] Swedish Coordination Council, "National action plan 2015-2030," 812 2014. [Online]. Available: http://www.swedishsmartgrid.se/english/thenational-action-plan/

[7] C. J. Wallnerström, L. Bertling Tjernberg, P. Hilber, S. Babu and J. H. Jürgensen, "Analys av smartaelnätsteknologier inom kategorin elnätslösningar," Sammordningsrådet för smarta elnät, Stockholm, 2014.

[8] D. Niyato, Q. Dong, P. Wang och E. Hossain, "Optimizations of Power Consumption and Supply in the Smart Grid: Analysis of the Impact of Data Communication Reliability," IEEE Trans. Smart Grid, vol. 4, nr 1, pp. $21-35,2013$.

[9] L. Ochoa, L. Cradden och G. Harrison, "Demonstrating the capacity benefits of dynamic ratings in smarter distribution networks," Innov. Smart Grid Technol. (ISGT), Gaithersburg, MD, USA, 2010.

[10] "Grid integration of large-capacity Renewable Energy sources and use of large-capacity Electrical Energy Storage," IEC, Geneva, Switzerland, 2012.

[11] S. Nursebo Salih, P. Chen, O. Carlson and L. Bertling Tjernberg, "Optimizing Wind Power Hosting Capacity of Distribution Systems Using Cost Benefit Analysis," IEEE Trans. on Power Delivery, vol. 29, pp. 1436 - 1445, June 2014

[12] P Wang, Z. Gao and L. Bertling Tjernberg, "Operational Adequacy Studies of Power Systems With Wind Farms and Energy Storages," IEEE Trans. on Power Systems, vol. 27, no. 4, pp. 2377-2384, 2012

[13] T. Broeer, J. Fuller, F. Tuffner, D. Chassin och N. Djilali, "Modeling framework and validation of a smart grid and demand response system for wind power integration," Applied Energy, vol. 113, pp. 199-207, 2014.

[14] D. Brodén, "Analysis of Demand Response Solutions for Congestion Management in Distribution Networks," KTH Royal Instiurute of Technology, Stockholm, Master thesis, 2013

[15] "Electrical Energy Storage," IEC, Geneva, Switzerland, 2011

[16] M. Lachman, P. Griffin, W. Walter och A. Wilson, "Real-time dynamic loading and thermal diagnostic of power transformers," IEEE Trans. on Power Delivery, vol. 18, pp. 142-148, 2003.

[17] C. J. Wallnerström, Y. Huang and L. Söder, "Impact from Dynamic Line Rating on Wind Power Integration," IEEE Trans. on Smart Grid, vol. 6 , nr 1, pp. 343 - 350, 2015

[18] A. Leite, C. Borges and D. Falcao, "Probabilistic wind farms generation model for reliability studies applied to Brazilian sites," IEEE Trans. on Power Systems, vol. 21, no. 4, pp. 1493-1501, 2006.

[19] L. Hernández, C. Baladrón, J. M. Aguiar, L. Calavia, C. Belén, A. Sánchez-Esguevillas, D. J. Cook, D. Chinarro och J. Gómez, ”A Study of the Relationship between Weather Variables and Electric Power Demand inside a Smart Grid/Smart World Framework," Sensors, vol. 12, nr 9, pp. 11571-11591, 2012.

[20] S. Babu, J. H. Jürgensen, C. J. Wallnerström, P. Hilber and L. Bertling Tjernberg, "Analyses of Smart Grid Technologies and Solutionsfrom a System Perspective," IEEE Power and Energy Society ISGT Asia 2015, Bangkok, Nov 2016

[21] N. Ekstedt, C. J. Wallnerström, S. Babu, P. Hilber, P. Westerlund, J. H. Jürgensen and T. Lindquist, "Reliability Data: A review of Importance, Use, and Availability," in NORDAC, Stockholm, 2014.

[22] "Swedish Meteorological and Hydrological Institute (SMHI)," [Online]. Available: http://www.smhi.se/en [Accessed Dec. 22 2014]. 
[23] C. J. Wallnerström, P. Hilber and J. Gadea Travi, "Implementation and evaluation of commonly used risk analysis methods applied to a regional power distribution system," CIRED, Stockholm, 2013.

[24] K. Chatziioannou, J. Guštinčič and L. Bertling Tjernberg, "On experience of smart grid projects in Europe and the Swedish demonstration projects," Chalmers, Göteborg, 2013.

[25] "Smart Grid Gotland," [Online].

Available: http://www.smartgridgotland.com/eng/ [Accessed Dec. 12 2014]

[26] C. J. Wallnerström and P. Hilber, "Vulnerability Analysis of Power Distribution Systems for Cost-Effective Resource Allocation," IEEE Trans. on Power Systems, vol. 27, no. 1, pp. 224-232, 2012.

[27] "IEEE Standard for Calculating the Current-Temperature of Bare Overhead Conductors," IEEE PES, New York, 2007.
[28] C. J. Wallnerström, J. Setréus, P. Hilber, F. Tong and L. Bertling, "Model of Capacity Demand under uncertain Weather," in PMAPS, Singapore, 2010.

[29] CIROTECH AB, "Solar data of Visby (at Latitude 57.5, Longitude 18.5)," [Online]. Available: http://www.cirotech.se/62141-visby.pdf [Accessed Dec. 20 2014].

[30] C. J. Wallnerström, P. Hilber, P. Söderström, R. Saers and O. Hansson, "Potential of dynamic rating in Sweden," in PMAPS, Durham, 2014.

[31] D. Susa and M. Lehtonen, "Dynamic thermal modeling of power transformers: Further development - part 1," IEEE Trans. on Power Delivery, vol. 21, pp. 1961 - 1970, Oct. 2006. 